\title{
Leiomyosarcoma of Urinary Bladder Following Cyclophosphamide Therapy: Report of Two Cases
}

\author{
C. Tanguay, M.D., I. Harvey, M.D., M. Houde, M.D., J. R. Srigley, M.D., B. Têtu, M.D. \\ Departments of Pathology, CHUQ (CT, IH, BT), Hôtel-Dieu de Québec, Laval University; Hôtel-Dieu \\ d'Arthabaska (MH), Victoriaville, Quebec; and Credit Valley Hospital (JRS), Mississauga, Ontario
}

\begin{abstract}
Leiomyosarcoma of urinary bladder is rare, although it is the most common mesenchymal tumor in adults. We report two cases of this tumor following cyclophosphamide therapy. The first case is from a 53-yearold man with Wegener's granulomatosis treated for 6 years with cyclophosphamide. He presented with painless hematuria, and the initial biopsy of the bladder tumor revealed a malignant spindle cell neoplasm. A final diagnosis of leiomyosarcoma was made on radical cystoprostatectomy. The second example is from a 21-year-old man who had received cyclophosphamide in early infancy for a bilateral retinoblastoma. He also presented with painless hematuria, and a bladder tumor was resected transurethrally and diagnosed as leiomyosarcoma. He underwent partial cystectomy two months later. Cyclophosphamide, when used for a neoplastic or non-neoplastic condition, is associated with an increased risk of developing bladder cancer. The distribution of histologic subtypes differs from that seen in spontaneous bladder tumors. A review of the literature shows an increased proportion of squamous cell carcinomas and sarcomas, especially leiomyosarcomas in cyclophosphamide exposed patients. Acrolein, a cytotoxic metabolite of cyclophosphamide excreted in urine, is regarded as the most likely causative agent.
\end{abstract}

KEY WORDS: Cyclophosphamide, Leiomyosarcoma, Urinary bladder.

Mod Pathol 2003;16(5):512-514

Benign and malignant mesenchymal tumors of the urinary bladder are rare. Leiomyosarcoma is the most common type, representing only $0.1 \%$ of bladder cancers (1). The median age of patients developing leiomyosarcoma is 49 years, but patients

Copyright () 2003 by The United States and Canadian Academy of Pathology, Inc.

VOL. 16, NO. 5, P. 512, 2003 Printed in the U.S.A.

Date of acceptance: February 21, 2003.

Address reprint requests to: Bernard Têtu, M.D., Department of Pathology, CHUQ, L'Hôtel-Dieu de Québec, 11, Côte du Palais, Québec, Canada, G1R 2J6; fax: 418-691-5226; e-mail: bernard.tetu@chuq.qc.ca.

DOI: 10.1097/01.MP.0000068237.38715.D9 ranging from 16 to 72 years have been reported (1-6). Since the first report by Rowland and Eble in 1983 (5), it has been established that the prevalence of bladder leiomyosarcoma is higher in cyclophosphamide-exposed patients $(1-4)$. The reason for this relationship remains speculative. We report two additional cases of this interesting association.

\section{REPORT OF CASES}

\section{Case 1}

A 53-year-old man who developed Wegener granulomatosis confirmed by nasal biopsy in 1979 was treated with prednisone and cyclophosphamide. In 1984, he presented with painless hematuria and cyclophosphamide was stopped. Cystoscopy revealed a sessile bladder tumor, and the initial biopsy showed a malignant spindle cell neoplasm (Fig. 1) with significant mitotic activity. The patient underwent radical cystoprostatectomy and received pre- and postoperative radiation therapy. A final diagnosis of leiomyosarcoma was made based on the presence of immunoreactivity (Avidin-biotin method of Hsu et al. [7]) for desmin (Dakopatts, Glostrup, Denmark, dilution: 1:200) and smooth muscle actin (Enzo, New York, dilution: 1:100). The myoglobin (Biogenex, San Ramos, CA, dilution: $1: 200$ ) stain was negative. Electron microscopy (fixation in $3 \%$ glutaraldehyde, postfixation in osmium tetroxide, counterstaining with uranyl acetate and lead citrate, analysis with a Zeiss EM109 electron microscope) showed spindle cells with bundles of thin myofilaments and dense bodies in the cytoplasm. The patient developed a local recurrence 6 months postsurgery and underwent further radiotherapy. The patient was lost to follow-up.

\section{Case 2}

A 21-year-old man with bilateral retinoblastoma was treated with left eye enucleation and right eye irradiation at 8 months of age. He received chemotherapy, including vincristine, actinomycin $\mathrm{D}$, and 


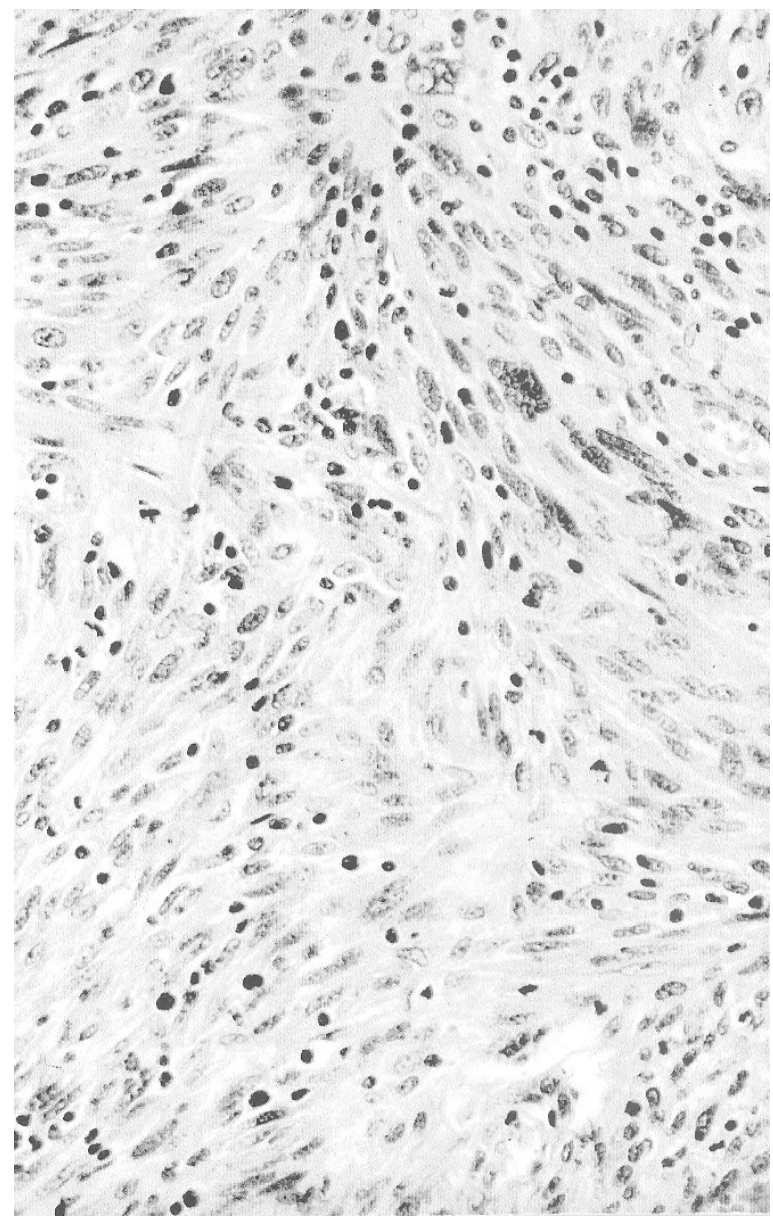

FIGURE 1. First case, leiomyosarcoma of urinary bladder (hematoxylin and eosin).

cyclophosphamide for unknown duration. Nineteen years after the initial treatment, he presented with recurrent retinoblastoma and was given another cycle of chemotherapy with carboplatin and VP 16. Shortly thereafter, he developed painless hematuria. A bladder tumor was found at the dome and was resected transurethrally. The specimen showed a spindle cell tumor (Fig. 2) with nuclear pleomorphism and a high mitotic rate (5-10 mitoses/10 HPF). The tumor expressed vimentin (Dakopatts, Glostrup, Denmark, clone V9, dilution: 1:50), desmin (Dakopatts, Glostrup, Denmark, dilution: 1:200), and smooth muscle actin (Dakopatts, Glostrup, Denmark, clone 1A4, dilution: 1:500) and was negative for keratin CAM 5.2 (BectonDickinson, San Jose, CA, dilution: 1:1) and epithelial membrane antigen (Dakopatts, Glostrup, Denmark, clone E29, dilution: 1:50). A diagnosis of leiomyosarcoma was made, and the patient underwent partial cystectomy. Little residual tumor was found on the surgical specimen. There was no recurrence at his last follow-up, 4 years after the partial cystectomy.

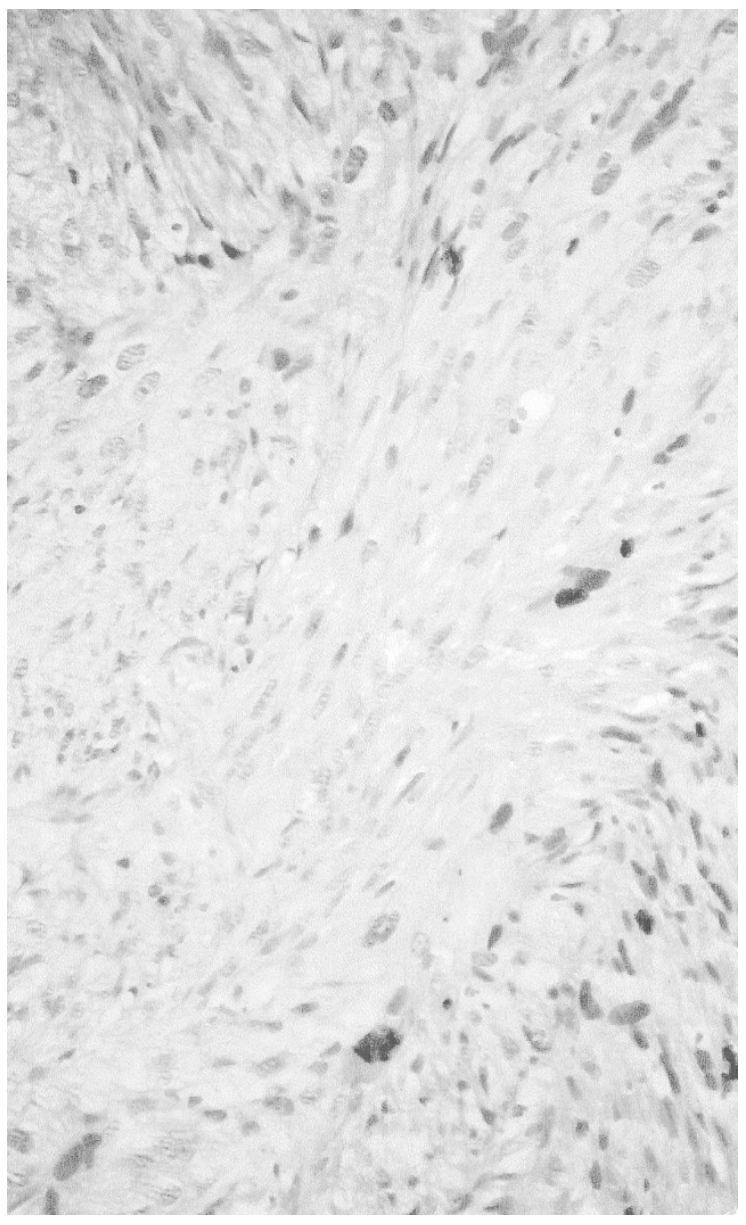

FIGURE 2. Second case, leiomyosarcoma of urinary bladder (hematoxylin and eosin).

\section{DISCUSSION}

Cyclophosphamide is a direct alkylating agent and is used as both a chemotherapeutic and immunosuppressive drug (4-6). It is activated in the liver by the cytochrome P-450, and all metabolites are excreted in the urine (5). The relative risk of developing bladder cancer is increased 6.8-fold in cyclophosphamide-exposed patients, and it ranges from 6.4 in absence of cystitis to 11.3 when hemorrhagic cystitis is present $(2,3)$. The risk appears to increase with time without reaching a plateau (2).

The distribution of histologic subtypes in cyclophosphamide-associated bladder cancers differs from that of sporadic cases. The proportion of squamous cell carcinomas increases from $2.7 \%$ in sporadic cases to $15.8 \%$ following cyclophosphamide, and that of transitional cell carcinomas decreases from $95.6 \%$ to $71.1 \%$. Adenocarcinomas remain unchanged and represent $1.5 \%$ of sporadic cases and $1.3 \%$ of cyclophosphamide-exposed patients (1). The proportion of mesenchymal neoplasms is increased, with leiomyosarcomas representing $9.2 \%$ of tumors in patients exposed to cyclophosphamide compared with $0.1 \%$ of sporadic 
TABLE 1. Cases of Cyclophosphamide-Associated Leiomyosarcoma

\begin{tabular}{|c|c|c|c|c|}
\hline Authors & Age/Sex & Diagnosis & $\begin{array}{c}\text { Duration of } \\
\text { Treatment }\end{array}$ & $\begin{array}{c}\text { Interval after } \\
\text { Diagnosis }\end{array}$ \\
\hline Rowland et al., 1983 (5) & $16 /$ male & Hodgkin's disease & 3.7 years & 12 years \\
\hline \multirow[t]{2}{*}{ Thrasher et al., 1990 (4) } & $51 /$ female & RA + nephritis & 11 years & 12 years \\
\hline & $60 /$ female & RA + nephritis & 7 years & 15 years \\
\hline Kawamura et al., 1993 (2) & $18 /$ male & Retinoblastoma & 6 years & 18 years \\
\hline Pedersen et al., 1995 (1) & $44 / \mathrm{male}$ & Non-Hodgkin's lymphoma & 3 years & 17 years \\
\hline Motta et al., 2001 (10) & $22 /$ female & Retinoblastoma & 5.7 years & 20 years \\
\hline Parekh et al., 2002 (8) & $22 /$ male & Retinoblastoma & $?$ & 21 years \\
\hline \multirow[t]{2}{*}{ Present study } & $53 /$ male & Wegener's & 5 years & 5 years \\
\hline & $21 /$ male & Retinoblastoma & $?$ & 19 years \\
\hline
\end{tabular}

cases. Fibrosarcomas account for $2.6 \%$ of treated cases compared with $0.019 \%$ of sporadic tumors (1).

In the literature, nine leiomyosarcomas, including ours, have been reported following treatment with cyclophosphamide (Table 1). Patients received the drug for either neoplastic or non-neoplastic conditions. The duration of treatment ranged from 3 (1) to 11 (4) years (median: 5.7 years), and the patients developed a leiomyosarcoma 5 (present study) to 21 years (8) (median: 17 years) after the initial diagnosis without dose- or time-related effect. Patients usually present with painless hematuria as the only symptom (4). Leiomyosarcomas occur mostly at the dome followed by the lateral walls of the bladder. Therefore, the best treatment is partial cystectomy, if feasible, in most cases (4).

The carcinogenic action appears to be secondary to excretion in urine of acrolein, one of the metabolites of cyclophosphamide (1-3). Acrolein causes acute toxicity to the bladder mucosa and can induce hemorrhagic cystitis $(2,4-6)$. This is followed by rapid epithelial regeneration and increased risk of mutation (3). One agent, sodium 2-mercaptoethanesulfonate, an acrolein inactivator, has been reported (2) to decrease the incidence of bladder cancer in rats and the risk of hemorrhagic cystitis in humans. There is, however, no further evidence that this drug can reduce the risk of developing bladder cancer in humans.

Mesenchymal changes mimicking radiation injuries, such as stromal edema, fibroblastic proliferation and degeneration, vascular alterations, and mucosal telangiectasia, have been observed with cyclophosphamide cystitis $(2,3,5,6)$. A possible relation of these atypical mesenchymal changes with the development of sarcomas has been proposed (2). However, occasional cases of leiomyosarcoma occur in patients with retinoblastoma without exposure to cyclophosphamide (9). Additionally some leiomyosarcomas show $\mathrm{pRb}$ and $\mathrm{p} 16$ gene abnormalities, suggesting that certain individuals may have inherited genetic susceptibility to develop such tumors (9). This genetically increased risk may be enhanced by the cyclophosphamide exposure.

In summary, the prevalence of leiomyosarcomas is increased in cyclophosphamide-exposed pa- tients. Acrolein, a cytotoxic metabolite of cyclophosphamide excreted in urine, is regarded as the potential causative agent. The premalignant mesenchymal lesion underlying the development of bladder sarcomas is not known, but it has been demonstrated that the relative risk is higher in patients with hemorrhagic cystitis. Patients on cyclophosphamide therapy should be followed closely.

Acknowledgments: The authors are thankful to Dr. Suzanne Boudreau, pathologist, Hôtel-Dieu d'Arthabaska, Victoriaville, Quebec, for her help at getting additional clinical information on case 2 .

\section{REFERENCES}

1. Pedersen-Bjergaard J, Jonsson V, Pedersen M, Hou-Jensen K. Leiomyosarcoma of the urinary bladder after cyclophosphamide. J Clin Oncol 1995;13:532-3.

2. Kawamura J, Sakurai M, Tsukamoto K, Tochigi H. Leiomyosarcoma of the bladder eighteen years after cyclophosphamide therapy for retinoblastoma. Urol Int 1993;51:49-53.

3. Sigal SH, Tomaszewski JE, Brooks JJ, Wein A, LiVolsi VA. Carcinosarcoma of bladder following long-term cyclophosphamide therapy. Arch Pathol Lab Med 1991;115:1049-51.

4. Thrasher JB, Miller GJ, Wettlaufer JN. Bladder leiomyosarcoma following cyclophosphamide therapy for lupus nephritis. J Urol 1990;143:119-21.

5. Rowland RG, Eble JN. Bladder leiomyosarcoma and pelvic fibroblastic tumor following cyclophosphamide therapy. J Urol 1983;130:344-6.

6. Chasko SB, Keuhnelian JG, Gutowski WT, III, Gray GF. Spindle cell cancer of bladder during cyclophosphamide therapy for Wegener's granulomatosis. Am J Surg Pathol 1980;4:191-6.

7. Hsu SM, Raine L, Fanger H. Use of avidin-biotin-peroxidase complex $(\mathrm{ABC})$ in immunoperoxidase techniques: a comparison between $\mathrm{ABC}$ and unlabeled antibody (PAP) procedures. J Histochem cytochem 1981;29:577-80.

8. Parekh DJ, Jung C, O'Conner J, Dutta S, Smith ER, Jr. Leiomyosarcoma in urinary bladder after cyclophosphamide therapy for retinoblastoma and review of bladder sarcomas. Urology 2002;60:164.

9. Liang SX, Lakshmanan Y, Woda BA, Jiang Z. A high-grade primary leiomyosarcoma of the bladder in a survivor of retinoblastoma. Arch Pathol Lab Med 2001;125:1231-4.

10. Motta L, Porcaro AB, Ficarra V, D’Amico A, Piubello Q, Communale L. Leiomyosarcoma of the bladder fourteen years after cyclophosphamide therapy for retinoblastoma. Scand J Urol Nephrol 2001;35:248-9. 